\title{
Fortification of reduced-fat Cheddar cheese with n-3 fatty acids: Effect on off-flavor generation
}

\author{
S. Martini, ${ }^{1}$ J. E. Thurgood, C. Brothersen, R. Ward, and D. J. McMahon \\ Western Dairy Center, Department of Nutrition and Food Sciences, Utah State University, Logan 84322-8700
}

\begin{abstract}
The objective of this study was to fortify $50 \%$ reduced fat Cheddar cheese with n-3 fatty acids and evaluate whether this fortification generated specific off-flavors in the cheese. Docosahexaenoic (DHA) and eicosapentaenoic (EPA) fatty acids were added to the cheese to obtain 3 final fortification levels [18, 35, and $71 \mathrm{mg}$ of DHA/EPA per serving size (28 g) of cheese] representing 10, 20, and $40 \%$ of the suggested daily intake level for DHA/EPA. The presence of oxidized, rancid, and fishy flavors as a function of fortification level and cheese aging (6 mo) was evaluated using a sensory descriptive panel. No differences were found in the oxidized and rancid flavors as a consequence of DHA/ EPA fortification, with only slight intensities of these flavors. The presence of fishy off-flavor was dependent on the fortification level. Cheeses with low fortification levels (18 and $35 \mathrm{mg}$ of DHA/EPA per serving size) did not develop significant fishy off-flavor compared with the control, whereas at the highest fortification level (71 mg of DHA/EPA per serving size) the fishy offflavor was significantly stronger in young cheeses. The fishy flavor decreased as a function of age and became nonsignificant compared with the control at 3 mo of storage. Even though fishy flavors were detected in the fortified cheeses, the DHA/EPA content during storage remained constant and complied with the suggested values for food fortification. Results obtained from this research indicate that $50 \%$ reduced-fat Cheddar cheese aged for 3 mo can be used as a vehicle for delivery of n-3 fatty acids without generation of off-flavors.
\end{abstract}

Key words: n-3 fatty acid, docosahexaenoic acid, eicosapentaenoic acid, reduced-fat Cheddar cheese

\section{INTRODUCTION}

Lipids are vital components of our diet; they are a source of energy and essential fatty acids. Some n-6 fatty acids such as linoleic and $\gamma$-linolenic acids are es-

Received November 6, 2008.

Accepted January 20, 2009.

${ }^{1}$ Corresponding author: Silvana.martini@usu.edu sential fatty acids that need to be incorporated into the diet as they cannot be synthesized by the body. The adequate intake recommended by the USDA for $\mathrm{n}-3$ and n-6 fatty acids is estimated at 1.0 to $1.6 \mathrm{~g} / \mathrm{d}$ and 12 to $17 \mathrm{~g} / \mathrm{d}$, respectively (USDA, 2005). Docosahexaenoic (DHA) and eicosapentaenoic (EPA) fatty acid are n-3 fatty acids that show beneficial health effects (Williams, 2000). The average intake of DHA and EPA fatty acids in Western societies in 2003 to 2004 was approximately 0.09 and $0.14 \mathrm{~g} / \mathrm{d}$ for females and males, respectively (USDA, 2007), showing a marginal intake in the consumption of these fatty acids.

Consumption of DHA and EPA has been associated with several health benefits. These fatty acids can help reduce the risk of coronary heart disease and reduce cancer; they also have antiinflammatory activity and proper neurological function (Sperling et al., 1993; Rose and Connolly, 1999; Williams, 2000; Kris-Etherton et al., 2003; Ruxton et al., 2004). Typically, DHA and EPA fatty acids are contained in oily fish such as salmon, lake trout, tuna, and herring. To meet the adequate intake levels recommended by USDA, oral supplements of n-3 fatty acids are available to consumers. Typically, oral supplements for adults contain $300 \mathrm{mg}$ of EPA, $200 \mathrm{mg}$ of DHA, and $100 \mathrm{mg}$ of other n-3 fatty acids, whereas supplements for children contain $100 \mathrm{mg}$ of DHA. An alternative to increase the consumption of n-3 fatty acids is to fortify foods with DHA and EPA. Several foods have been supplemented with DHA/EPA, from confectionery to dairy products (Avramis et al., 2003; Kolanowski and Weißbrodt, 2007), sausages, meat (Scollan et al., 2006), milk (Lock and Bauman, 2004), margarine spreads (Metcalf et al., 2003; Kolanowski et al., 2004), cookies (Borneo et al., 2007), and bread (Murphy et al., 2007). Fortification of cheese has also been performed using DHA/EPA-fortified milk or by directly incorporating DHA/EPA during cheesemaking. Avramis et al. (2003) made Cheddar cheese using milk from cows fed fish meal and observed no sensory effect in the cheeses; however, levels of DHA/EPA in the cheese were not measured. Aryana (2007) substituted $100,50,25$, and $0 \%$ of the fat in cheese with OmegaPure (Houston, TX), a commercial oil rich in $\mathrm{n}-3$ fatty acids and found a significant difference between the flavors of 
cheeses fortified with n-3 fatty acids compared with the control cheeses (0\% DHA).

Docosahexaenoic acid and EPA are polyunsaturated fatty acids. These highly unsaturated fatty acids tend to oxidize, generating typical oxidized, rancid, or fishy off-flavors. When incorporating n-3 fatty acids in foods it is vital to achieve the desired concentration in the food product without causing formation of the typical off-flavors associated with polyunsaturated fatty acids. Therefore, the sensory quality of foods supplemented with DHA/EPA needs to be closely evaluated to ensure good consumer acceptance.

The objective of this research was to manufacture $50 \%$ reduced-fat Cheddar cheese with increased levels of DHA and EPA using an encapsulated fish oil powder and evaluate the presence of oxidized, rancid, and fishy flavors in the fortified cheeses using a sensory descriptive panel. The levels of fortification used were 18, 35, and $71 \mathrm{mg}$ of DHA/EPA per serving size (28 g), which represent approximately 10, 20, and $40 \%$ of the suggested daily intake level for DHA/EPA. The oxidized, rancid, and fishy flavor intensities as a function of DHA/EPA fortification level and cheese age $(6 \mathrm{mo})$ were evaluated by a sensory descriptive panel.

\section{MATERIALS AND METHODS}

\section{Cheese Manufacturing Method}

Reduced-fat Cheddar cheese curd was made from $227 \mathrm{~kg}$ of pasteurized $\left(73^{\circ} \mathrm{C}, 15 \mathrm{~s}\right.$ ) milk (Gary Haight Richardson Dairy Products Laboratory at Utah State University, Logan) standardized to a protein to fat ratio of 1.9. Sixty grams of Lactococcus lactis starter culture (DVS850, Chr. Hansen Laboratories, Milwaukee, WI) was added to the milk at $31^{\circ} \mathrm{C}$, ripened for $40 \mathrm{~min}$, and then set using $20 \mathrm{~mL}$ of double-strength chymosin (Maxiren, DSM Food Specialties, Menomonee Falls, WI). The curd was cut using 16-mm curd knives in the vertical direction only, healed, and then cooked to $36^{\circ} \mathrm{C}$ over $15 \mathrm{~min}$. Whey was drained when curd $\mathrm{pH}$ reached 6.20 (set-to-drain time $\sim 90 \mathrm{~min}$ ) and curd was washed by adding enough water (at $18^{\circ} \mathrm{C}$ ) to lower the curd temperature to $29^{\circ} \mathrm{C}$. After $10 \mathrm{~min}$, the wash water was drained and the curd stirred until $\mathrm{pH}$ reached 5.9 and then divided into portions to manufacture the fortified and control cheeses.

\section{DHA/EPA Source}

Samples of DHA/EPA were provided by Ocean Nutrition (Dartmouth, Nova Scotia, Canada). The material consisted of microencapsulated fish oil. In this product, the fish oil is encapsulated using the Powder-loc micro- encapsulation technology (Ocean Nutrition) resulting in a powder of approximately $60 \mu \mathrm{m}$ of diameter. The certificate of analysis of the powder indicates that $95.3 \%$ passes through a 140-mesh sieve and $99 \%$ of the powder passes through a 100-mesh sieve. For more detail on the product characteristics, please refer to http://www. ocean-nutrition.com/Products/FI/fimeg3real.php\# Tech.

\section{Addition of n-3 Fatty Acids}

Cheese fortification was performed by grinding the curd with the DHA/EPA encapsulated material. To obtain a fortification level of 18,35 , and $71 \mathrm{mg}$ of DHA/EPA per serving size (28 g), 3 portions (1.4 $\mathrm{kg}$ ) of ground salted curd obtained as described below (ground control) were blended with 4.8, 9.6, or 19.2 $\mathrm{g}$ of encapsulated DHA/EPA powder (MEG-3, Ocean Nutrition) in a bowl mixer (model KSM5, KitchenAid, St. Joseph, MI) and pressed overnight. The encapsulated DHA/EPA material contained $179 \mathrm{mg}$ of DHA/ EPA per gram. All cheeses (controls and fortified) were then vacuum packaged and stored at $8^{\circ} \mathrm{C}$. Cheeses were made in triplicate over a 3 -wk period. Sensory evaluation was performed at 1 and $7 \mathrm{~d}$, and 1,3 , and $6 \mathrm{mo}$ of age.

\section{Controls}

Ground Control. A ground control cheese (without the addition of DHA/EPA) was obtained by grinding $13.6 \mathrm{~kg}$ of fresh, unsalted cheese curd with $340 \mathrm{~g}$ of salt for $30 \mathrm{~s}$ (model VCM 25, Hobart, Troy, OH). A $2.7-\mathrm{kg}$ portion of this salted curd was packed into round hoops and pressed overnight at $20.7 \mathrm{kPa}$. The rest of the curd was used to manufacture the fortified cheeses as described above (addition of n-3 fatty acids).

Nonground Control. To confirm that the grinding process did not incorporate off-flavors in the cheese, a nonground control cheese was also included in the experimental design. This control was obtained by adding salt $(68 \mathrm{~g})$ to the curd $(2.7 \mathrm{~kg})$ in 3 applications 5 min apart and then pressing in a round plastic hoop overnight at $20.7 \mathrm{kPa}$. All control cheeses were made in triplicate over a 3 -wk period.

\section{Proximate Analysis}

The $\mathrm{pH}$, moisture, fat, and salt contents were determined for all cheeses at $5 \mathrm{~d}$ of age. Cheese $\mathrm{pH}$ was determined by combining $20 \mathrm{~g}$ of finely grated cheese with $10 \mathrm{~g}$ of water in a plastic bag and stomaching (Stomacher model 400, Seward, Riverview, FL) at 260 $\mathrm{rpm}$ for $1 \mathrm{~min}$. The $\mathrm{pH}$ of this slurry was measured 
using a Xerolyt combination electrode (model HA405, Mettler Toledo, Columbus, $\mathrm{OH}$ ) and an Accumet $\mathrm{pH}$ meter (model AR 25, Fisher Scientific, Pittsburgh, PA). Moisture content was measured in triplicate using a CEM microwave oven (CEM Corp., Indian Trail, NC). Fat content was determined using the Babcock method (method 15.8.A; American Public Health Association, 1992). Salt content was measured by combining $5 \mathrm{~g}$ of finely grated cheese with $98.2 \mathrm{~g}$ of water and mixing for $4 \mathrm{~min}$ at $260 \mathrm{rpm}$ in a Stomacher 400 (Seward). The slurry was filtered through a Whatman no. 1 filter paper, and the filtrate was analyzed for sodium chloride using a chloride analyzer (model 926, Corning, Medfield, MA).

\section{Sensory Evaluation}

The presence of oxidized, rancid, and fishy flavors in fortified and control cheeses was evaluated using a descriptive panel. Thirteen panelists, selected according to their availability and interest in participating in this study, received an initial $13 \mathrm{~h}$ of training, during which they were taught to correctly identify and quantify oxidized, rancid, and fishy flavors. During the tasting period $(180 \mathrm{~d})$, panel maintenance consisted of 1 training session before each tasting session. The panel consisted of 7 women and 6 men between 24 and $60 \mathrm{yr}$ old. The training and tests were performed in the Sensory Evaluation Facilities in the Department of Nutrition and Food Sciences at Utah State University. These facilities consisted of a kitchen where cheese samples were cut, placed in 2-oz. cups, covered with a lid, and left at room temperature until tasting. Samples were always served at room temperature. Trainings were performed at a round table in the kitchen, whereas tasting was performed in individual booths under fluorescent light.

For the training and maintenance sessions, reference cheeses were prepared to represent the attributes of interest. Reference cheeses were prepared using $1.4 \mathrm{~kg}$ of freshly prepared cheese curd that was ground with salt using the method described above for ground control cheeses. Two levels of oxidized flavor in the cheese were obtaining by thoroughly mixing (KitchenAid, model KSM5) 5 or $12 \mathrm{~mL}$ of a $1 \%$ solution of $\mathrm{CuSO}_{4}$ with the ground curd (Shipe et al., 1978). Cheeses were aged for at least 2 wk to allow flavor development before tasting. Rancid flavor references were prepared by thoroughly mixing 60 or $120 \mathrm{~g}$ of Feta cheese (Utah State University Dairy Products Laboratory, Logan) to the $1.4 \mathrm{~kg}$ of freshly made cheese curd. Finally, 3 levels of fishy cheese were prepared by thoroughly mixing 4.8, 9.6, or $9.2 \mathrm{~g}$ of encapsulated DHA/EPA powder (MEG-3, Ocean Nutrition), which on its own has an intense fishy flavor attribute, in $1.4 \mathrm{~kg}$ of the freshly made cheese curd.

During training and tasting sessions, panelists were asked to take a bite of the sample, keep it in their mouth for a couple of seconds, expectorate, and evaluate the intensity of oxidized, rancid, and fishy flavor using a 5-point category scale with the following categories: no flavor, slight flavor, moderate flavor, strong flavor, and extremely strong flavor. For statistical analysis, numerical scores of $0=$ no flavor, $1=$ slight flavor, $2=$ moderate flavor, $3=$ strong flavor, and $4=$ extremely strong flavor were assigned to the category scale. Panelists were instructed to follow good sensory practices as described by Meilgaard et al. (2007). Unsalted crackers and water were provided to rinse the palate between samples.

Of the original 13 panelists that volunteered to participate in the study, 2 panelists had poor attendance and their attribute ratings were discarded. Additionally, some panelists demonstrated an inability to correctly identify and accurately rate one or more of the flavor attributes being studied, so they were removed from the analyses of such. Therefore, the number of panelists included in the statistical analyses of the oxidized, rancid, and fishy flavor attribute ratings, respectively, were 10,9 , and 9 .

Before training and tasting, approval from the Utah State University Institutional Review Board was obtained to use human subjects in the panel. Sensory evaluation of the experimental cheeses was performed at 1 (same day as cheese was removed from the press) and $7 \mathrm{~d}$, and 1, 3, and 6 mo after manufacture.

\section{Fatty Acid Composition}

Fatty acids were measured quantitatively in the cheese samples as methyl ester derivatives by the method of Ocean Nutrition (Curtis et al., 2008). According to the method, the C19:0 synthetic triglyceride trinonadecanoin was used as a surrogate spike to calculate analyte recovery, and the C23:0 methyl ester tricosanoic acid was used as an internal standard. In addition, 3 GC reference standards, GLC 409, GLC 461, and GLC 603 , were used to identify peaks and to establish instrument response factors for each fatty acid methyl ester of interest. All lipid reference materials were purchased from Nu-Chek Prep Inc. (Elysian, MN).

Fatty acid methyl esters were analyzed using a Shimadzu QP2010s GC/MS (Shimadzu, Tokyo, Japan) equipped with an Agilent HP-88 column $(100 \mathrm{~m} \times 0.25$ $\mathrm{mm}$ i.d. $\times 0.2-\mu \mathrm{m}$ film thickness; Agilent, Santa Clara, CA) and a flame-ionization detector. The injector was operated in split mode (50:1 split ratio), and hydrogen 
was used as the carrier gas at a fixed linear velocity of $41.1 \mathrm{~cm} / \mathrm{s}$. The injector temperature was maintained at $250^{\circ} \mathrm{C}$. The following temperature program was used: initial temperature $50^{\circ} \mathrm{C}$, held 1 min, increased at $40^{\circ} \mathrm{C} /$ min to $175^{\circ} \mathrm{C}$ and held for $4 \mathrm{~min}$, increased at $3.5^{\circ} \mathrm{C}$ to $250^{\circ} \mathrm{C}$ and held for $3 \mathrm{~min}$. The total program time was $32.55 \mathrm{~min}$. The flame-ionization detector was operated using the following parameters: temperature of $250^{\circ} \mathrm{C}$, nitrogen makeup flow at $30 \mathrm{~mL} / \mathrm{min}$, air at $450 \mathrm{~mL} /$ min, and hydrogen at $40 \mathrm{~mL} / \mathrm{min}$.

\section{Statistical Analysis}

For statistical analysis, numerical scores of $0=$ no flavor, 1 = slight flavor, $2=$ moderate flavor, $3=$ strong flavor, and $4=$ extremely strong flavor were assigned to the category scale. Cheeses were made in triplicate and a repeated-measures design using an autoregressive correlation structure was used to analyze the effect of n-3 fatty addition and age on the intensity of oxidized, rancid, and fishy flavors. Samples were presented to panelists in a randomized complete block design. Sensory data was collected using SIMS 2000 (Morristown, NJ) and statistical analysis was performed using SAS 9.1.3 (SAS Institute, Cary, NC).

\section{RESULTS AND DISCUSSION}

\section{Proximate Analysis}

No differences $(P>0.05)$ were found between the proximate analysis of the controls (nonground and ground) and the n-3 fortified cheeses (different fortification levels). The nonground cheese had slightly lower moisture content than the ground cheeses (data not shown). Table 1 summarizes the average values and standard errors obtained for the controls and the fortified cheeses. Standard of identity for full-fat Cheddar cheese indicate that these types of product should contain approximately $37 \%$ moisture and $33 \%$ fat. As expected for $50 \%$ reduced-fat Cheddar cheeses, moisture, fat, salt and $\mathrm{pH}$ values were approximately $47 \%$, $16 \%, 1.8 \%$, and 5.2 , respectively.

\section{Sensory Evaluation}

No differences $(P>0.05)$ were found between the ground and nonground controls for any of the attributes examined over the time of the study, with $P$-values of $0.72,0.69$, and 0.76 for oxidized, rancid, and fishy, respectively. Therefore, only the data for the ground control cheese are discussed from this point forward.

Figures 1, 2, and 3 show the descriptive panel scoring for oxidized, rancid, and fishy attributes, respectively.
Table 1. Proximate analysis (mean \pm SE) for control and fortified cheeses

\begin{tabular}{lcc}
\hline Item & Control & Fortified cheeses \\
\hline Moisture (\%) & $47.20 \pm 1.35$ & $48.12 \pm 0.17$ \\
Fat (\%) & $16.17 \pm 0.33$ & $16.17 \pm 0.17$ \\
Salt (\%) & $1.83 \pm 0.10$ & $1.98 \pm 0.12$ \\
$\mathrm{pH}$ & $5.20 \pm 0.08$ & $5.27 \pm 0.06$ \\
\hline
\end{tabular}

No differences $(P>0.05)$ were found between the oxidized flavor as a function of DHA/EPA addition and age (Figure 1). Average rating for all samples were $\leq 1.0$, indicating a very slight level of this flavor. Even though differences were not significant, a slight increase in oxidation scores was observed with aging, especially for the control cheese for which the score increased from $0.3(1 \mathrm{~d})$ to 0.7 (6 mo).

Figure 2 shows the scores for rancid flavor obtained for the fortified and control cheeses. Fortification level did not affect the intensity of rancid flavor $(P>0.05)$. However, a significant increase in rancid flavor was observed as a function of aging $(P=0.0007)$. Sensory scores were slightly higher for rancid flavor than for oxidized flavor, with values between 0.5 and 1.0. The increase in rancid flavor notes in cheeses as a function of aging is expected and not necessarily a defect. Figure 3 shows the sensory scores obtained for fishy flavors detected in the fortified and control cheeses. Both fortification level and age significantly $(P<0.05)$ affected the intensity of fishy flavors in the cheeses. The greater the amount of n-3 fatty acids added, the stronger the fishy flavor, especially for short aging times. Fishy notes decreased as a function of aging, and no significant differences were found between any of the fortified cheeses and the control at 3 mo of age. Table 2 shows a summary of the differences in fishy flavor detection between the fortification level and aging times. Significance levels between the samples and the average values for fishy flavor (diagonal values) are shown in this table. For clarity, standard errors are omitted in this table. Standard error values were low and ranged from 0 to 0.1 . Table 2 shows that no differences $(P>0.05)$ between the control and the cheeses with 18 and $35 \mathrm{mg}$ of DHA/EPA were observed at any aging time. Average and standard error scores for the fishy attribute were $0.2 \pm 0.1,0.3 \pm 0.1$, and $0.8 \pm$ 0.2 for the control (0 mg of DHA and EPA) and the lowest fortification levels (18 and $35 \mathrm{mg}$ of DHA/EPA), respectively, for $\mathrm{d} 1$, and decreased with aging. Differences were found between the control and the cheese fortified with $71 \mathrm{mg}$ of DHA/EPA $(P<0.001)$, with an average score for the fishy flavor of 1.2 for $\mathrm{d} 1$. However, this value was not significantly different from the fishy flavor obtained for the cheese with $35 \mathrm{mg}$ of DHA/EPA 


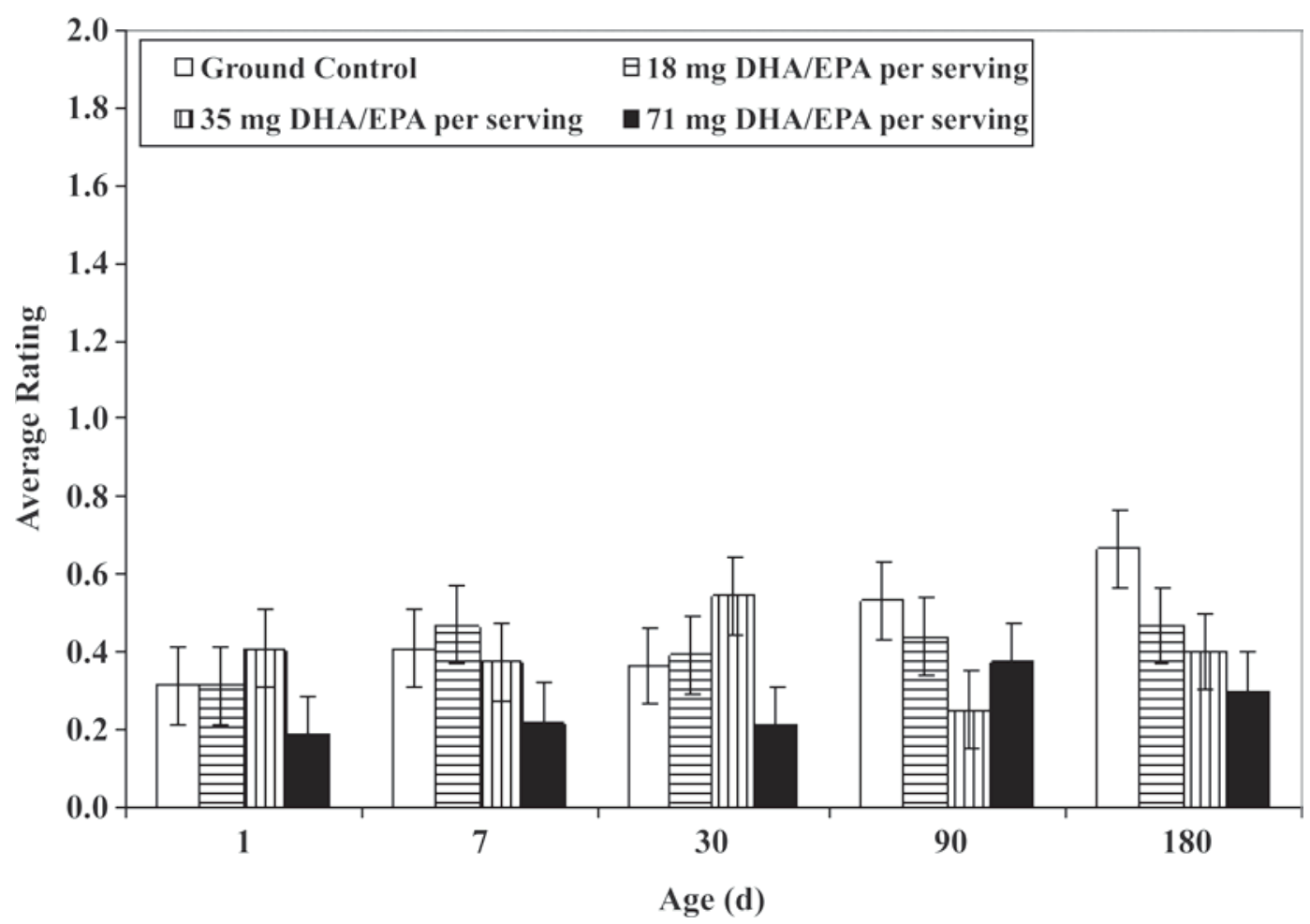

Figure 1. Average sensory panel score for oxidized attribute as a function of level of fortification level and age. Sensory scores: $0=$ no flavor; $1=$ slight flavor; $2=$ moderate flavor; $3=$ strong flavor; and $4=$ extremely strong flavor. Bars represent standard errors. DHA $=$ docosahexaenoic acid; $\mathrm{EPA}=$ eicosapentaenoic acid.

$(P>0.05)$, but became significant at $7 \mathrm{~d}$ of aging $(P<$ $0.05)$ as a consequence of a decrease in the fishy flavor intensity for the cheese fortified with $35 \mathrm{mg}$ of DHA/ EPA. As aging time increased, the fishy flavor intensity decreased for all samples, with scores between 0 and 0.5 for 3 and 6 mo of storage. The greatest decrease in fishy flavor intensity was observed for the highest fortification level $(71 \mathrm{mg})$, from $1.2 \pm 0.2$ at $1 \mathrm{~d}$ to $1.0 \pm 0.2$, $0.5 \pm 0.1$, and $0.3 \pm 0.1$ for 1,3 , and 6 mo respectively. Consequently, differences between the cheeses fortified with $71 \mathrm{mg}$ of DHA/EPA and the control became nonsignificant at $3 \mathrm{mo}$ of age. It is interesting to note here, that even though a fishy note was detected for the fortified cheeses, the intensity was never rated above 1.2 , indicating only a slight intensity of this off-flavor.

\section{DHA/EPA Content}

The encapsulated powder used for n-3 fortification of the cheeses was listed as containing $179 \mathrm{mg}$ of DHA/ EPA per gram of powder and the quantities added to the cheese curd were selected to provide 18, 35, and $71 \mathrm{mg}$ of DHA/EPA per 28-g (1-oz) serving of cheese. Fatty acid analysis of the cheeses showed that, on average, fortified cheeses contained $0,18,35$, and 71 mg of DHA/EPA per $28 \mathrm{~g}$ of cheese for the control and n-3 fortified cheeses, respectively, which is in accordance with the target values and well within the ranges proposed for providing 10,20, and $40 \%$ of the recommended daily level for DHA/EPA (Table 3). No differences $(P>0.05)$ were found in DHA/EPA content of cheeses with aging. Even though the highly fortified cheeses had a fishy flavor at early aging times, which we assumed to be a consequence of the oxidation of the DHA/EPA fatty acids, the degree of oxidation was not enough to significantly affect the total content of these fatty acids in the cheese. Most importantly, the decrease in the fishy flavor with age was not due to a lack of substrate for oxidation but might be attributed to other causes such as other flavor developments during cheese age, changes in texture, or decrease in moisture content.

\section{CONCLUSIONS}

Fortification of Cheddar cheeses with low amounts (18 and $32 \mathrm{mg} /$ serving size) of n-3 fatty acids does not produce any off-flavor in the cheese. Higher fortification levels (71 mg/serving size) result in a slight fishy flavor at early stages of aging. This off-flavor diminishes 


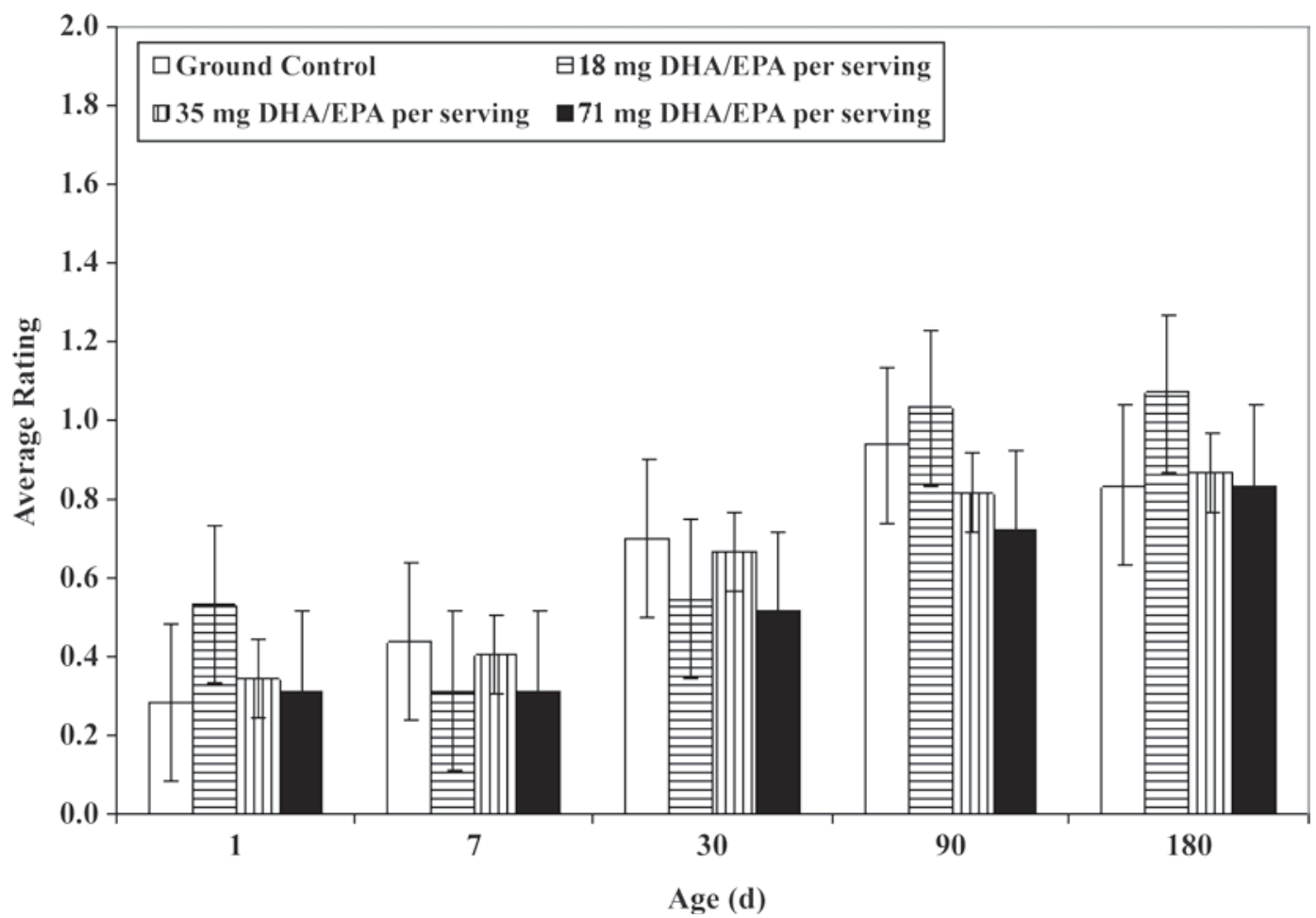

Figure 2. Sensory panel score for rancid attribute as a function of fortification level and age. Sensory scores: $0=$ no flavor; $1=$ slight flavor; $2=$ moderate flavor; $3=$ strong flavor; and $4=$ extremely strong flavor. Bars represent standard errors. DHA $=$ docosahexaenoic acid; EPA $=$ eicosapentaenoic acid.

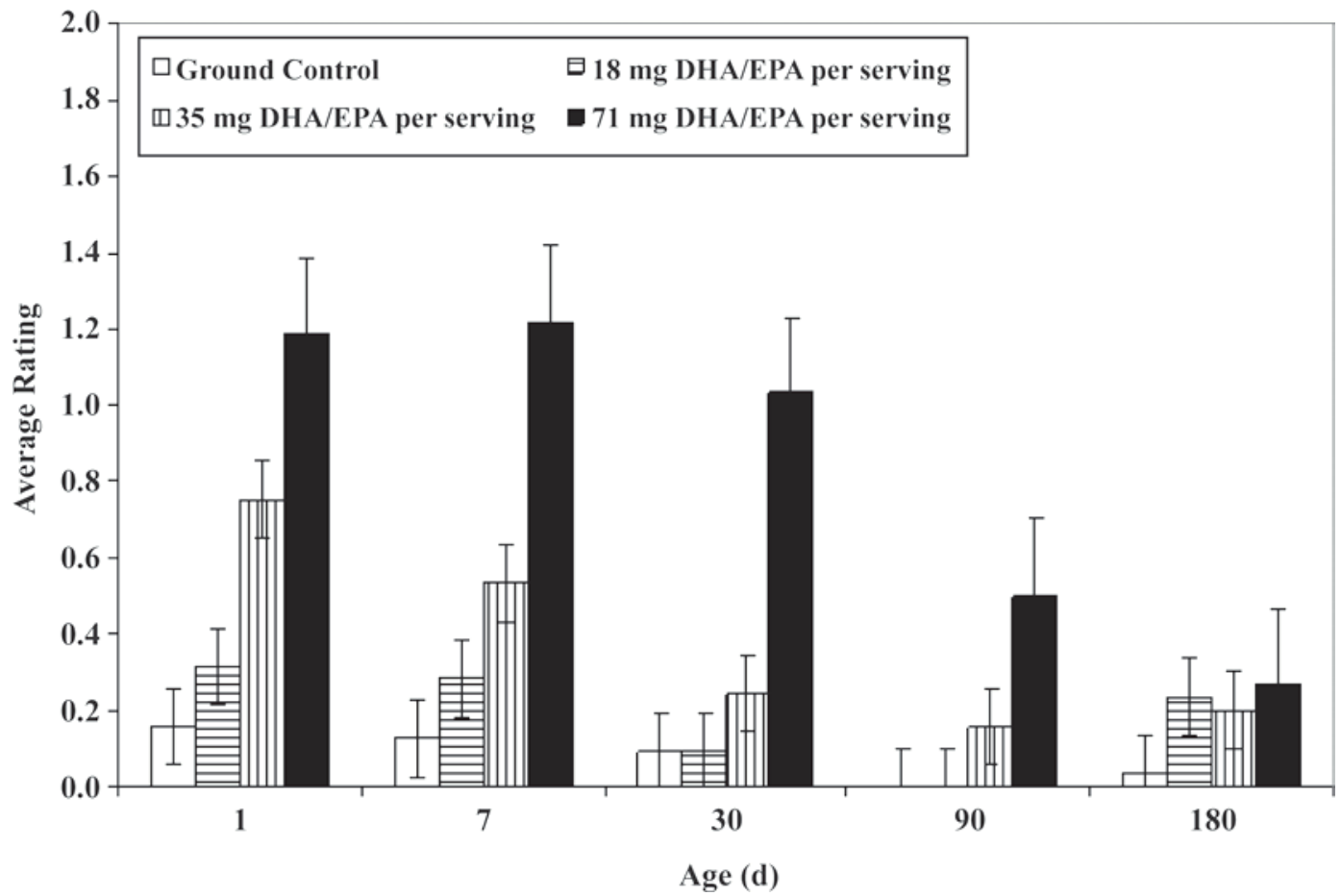

Figure 3. Sensory panel score for fishy attribute as a function of fortification level and age. Sensory scores: $0=$ no flavor; $1=$ slight flavor; $2=$ moderate flavor; $3=$ strong flavor; and $4=$ extremely strong flavor. Significant differences between samples and aging times are shown in Table 2. Bars represent standard errors. DHA = docosahexaenoic acid; EPA = eicosapentaenoic acid 
Table 2. Significant differences in the fishy flavor for cheeses fortified with n-3 fatty acids at 0, 18, 35, and $71 \mathrm{mg}$ of docosahexaenoic and eicosapentaenoic fatty acids (per 28-g serving size) and aged for $180 \mathrm{~d}^{1}$

\begin{tabular}{|c|c|c|c|c|c|c|c|c|c|c|c|c|c|c|c|c|c|c|c|c|c|}
\hline \multirow{2}{*}{$\begin{array}{l}\text { Age } \\
\text { (d) }\end{array}$} & \multirow{2}{*}{$\begin{array}{l}\text { Fortification, } \\
\mathrm{mg} / \text { serving size }\end{array}$} & \multicolumn{4}{|c|}{ d 1} & \multicolumn{4}{|c|}{ d 7} & \multicolumn{4}{|c|}{ d 30} & \multicolumn{4}{|c|}{ d 90} & \multicolumn{4}{|c|}{ d 180} \\
\hline & & 0 & 18 & 35 & 71 & 0 & 18 & 35 & 71 & 0 & 18 & 35 & 71 & 0 & 18 & 35 & 71 & 0 & 18 & 35 & 71 \\
\hline \multirow[t]{4}{*}{1} & 0 & 0.2 & & & $* *$ & & & & $* *$ & & & & * & & & & & & & & \\
\hline & 18 & & 0.3 & & $*$ & & & & $* *$ & & & & $*$ & & & & & & & & \\
\hline & 35 & & & 0.8 & & & & & & & & & $*$ & $*$ & $*$ & & & $*$ & & & \\
\hline & 71 & $* *$ & $*$ & & 1.2 & $* *$ & $* *$ & $*$ & & $* *$ & $* * *$ & $*$ & & $* * *$ & $* * *$ & $* *$ & & $* * *$ & $* *$ & $* *$ & $* *$ \\
\hline \multirow[t]{4}{*}{7} & 0 & & & & $* *$ & 0.1 & & & $* * *$ & & & & $* *$ & & & & & & & & \\
\hline & 18 & & & & $* *$ & & 0.3 & & $* *$ & & & & $*$ & & & & & & & & \\
\hline & 35 & & & & * & & & 0.5 & $*$ & & & & & & & & & & & & \\
\hline & 71 & $* *$ & $* *$ & & & $* * *$ & $* *$ & $*$ & 1.2 & $* * *$ & $* * *$ & $* *$ & & $* * *$ & $* * *$ & $* *$ & & $* * *$ & $* *$ & $* *$ & $* *$ \\
\hline \multirow[t]{4}{*}{30} & 0 & & & & $* *$ & & & & $* * *$ & 0.1 & & & $* *$ & & & & & & & & \\
\hline & 18 & & & $*$ & $* * *$ & & & & $* * *$ & & 0.1 & & $* *$ & & & & & & & & \\
\hline & 35 & & & & $*$ & & & & $* *$ & & & 0.2 & $*$ & & & & & & & & \\
\hline & 71 & $*$ & $*$ & & & $* *$ & $*$ & & & $* *$ & $* *$ & $*$ & 1.0 & $* * *$ & $* * *$ & $*$ & & $* * *$ & $*$ & $* *$ & $*$ \\
\hline \multirow[t]{4}{*}{90} & 0 & & & $*$ & $* * *$ & & & & $* * *$ & & & & $* * *$ & 0.0 & & & & & & & \\
\hline & 18 & & & $*$ & $* * *$ & & & & $* * *$ & & & & $* * *$ & & 0.0 & & & & & & \\
\hline & 35 & & & & $* *$ & & & & $* *$ & & & & $*$ & & & 0.2 & & & & & \\
\hline & 71 & & & & & & & & & & & & & & & & 0.5 & & & & \\
\hline \multirow{4}{*}{180} & 0 & & & $*$ & $* * *$ & & & & $* * *$ & & & & $* * *$ & & & & & 0.0 & & & \\
\hline & 18 & & & & $* *$ & & & & $* *$ & & & & $*$ & & & & & & 0.2 & & \\
\hline & 35 & & & & $* *$ & & & & $* *$ & & & & $* *$ & & & & & & & 0.2 & \\
\hline & 71 & & & & $* *$ & & & & $* *$ & & & & $*$ & & & & & & & & 0.3 \\
\hline
\end{tabular}

${ }^{1}$ Values on the diagonal are the average fishy flavor intensity; sensory scores are $0=$ no flavor; $1=$ slight flavor; $2=$ moderate flavor; $3=$ strong flavor; and $4=$ extremely strong flavor. Standard errors are not reported for simplicity.

${ }^{*} P<0.05 ;{ }^{* *} P<0.001 ;{ }^{* *} P<0.0001$; significant difference of the means. 
Table 3. Response factors and fatty acid composition ( $\mathrm{mg}$ of fatty acids per $\mathrm{g}$ of dried cheese) of the $50 \%$ reduced-fat Cheddar cheeses fortified with different levels $(0,18,35$, or $71 \mathrm{mg}$ per 28 -g serving size) of n-3 fatty acids

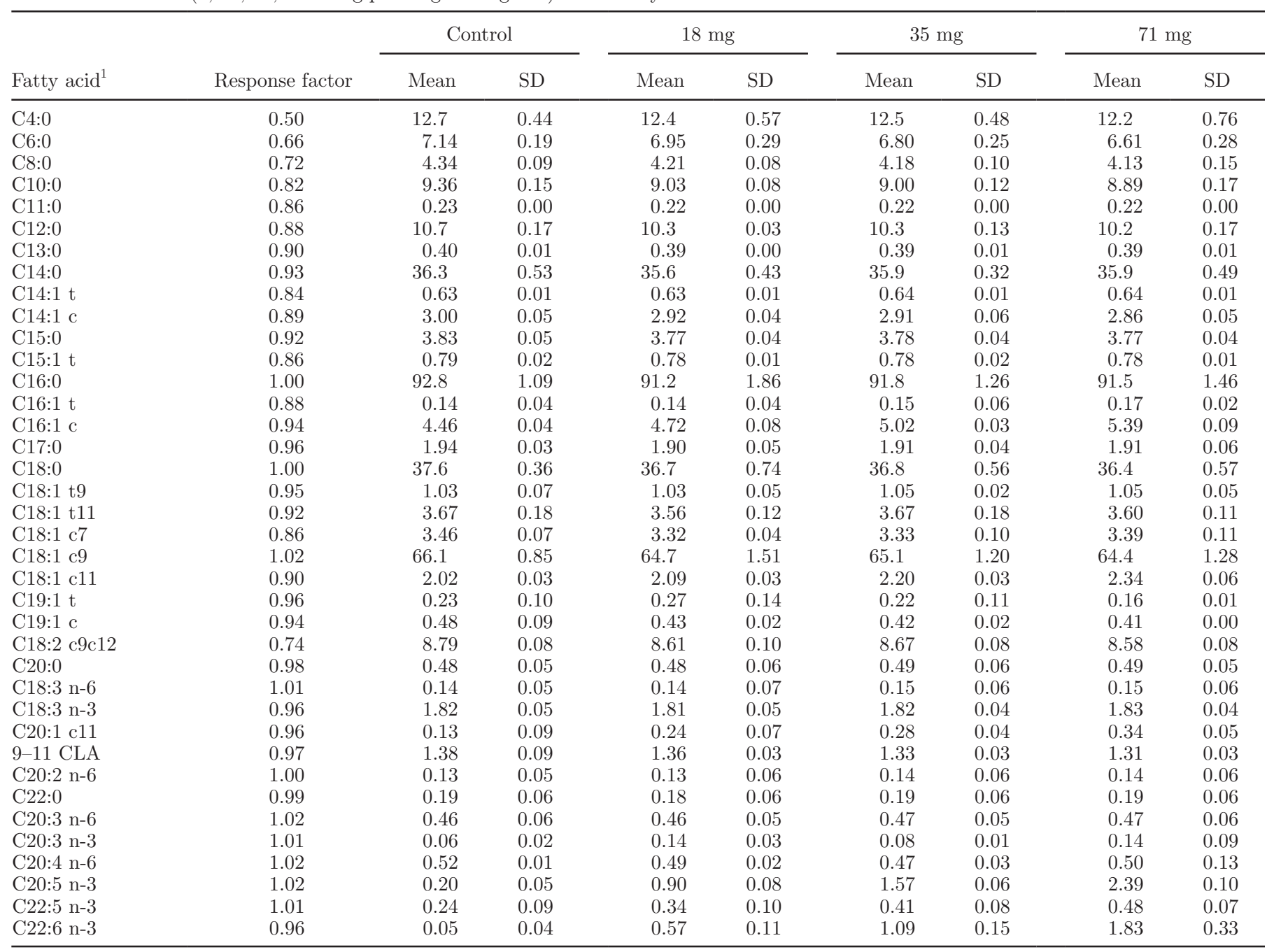

${ }^{1} \mathrm{c}=$ cis $; \mathrm{t}=$ trans $;$ CLA $=$ conjugated linoleic acid.

as a function of cheese age, with no differences found between the control and the fortified cheeses at 3 mo of aging. Even though the fishy off-flavor decreased during aging, DHA/EPA remained constant as shown by the GC data indicating that $50 \%$ reduced-fat Cheddar cheese can be fortified with n-3 fatty acids, specifically DHA/EPA, without affecting the flavor profile of the cheese, if aged for 3 mo or longer. Fishy off-flavors most likely originate as a consequence of oxidation of the $n-3$ polyunsaturated fatty acids. This chemical reaction is catalyzed by the presence of oxygen, light, and metals. Briefly, the oxidation of lipids is a self-propagating reaction mediated by the generation of free radicals. The reaction ends when free radicals combine and generate non-free-radical compounds. These compounds are short-chain aldehydes, alcohols, and esters that, because of their volatility, impart the characteristic off-flavor of oxidized products (White, 2000; Venkateshwarlu et al., 2004a,b; Ganeko et al., 2008). The decrease in fishy off-flavor with aging might be due to 1) a reduction in the oxidation rate of the polyunsaturated fatty acids present in the cheese due to the low redox potential of cheese; 2) the disappearance of fishy off-flavors as a consequence of bacterial metabolism; or 3) the masking effect of flavors developed during cheese aging. More research is needed to evaluate the factors that control generation of fishy off-flavor in reduced-fat Cheddar cheeses and to understand its dissipation during storage. Such experiments should include solid-phase microextraction analyses of the cheeses as a function of aging and a complete characterization of the flavor profile of the fortified cheeses. 


\section{ACKNOWLEDGMENTS}

Financial support for this project was provided by DMI Inc. (Rosemont, IL), The Western Dairy Center (Logan, UT), and Utah Agricultural Experiment Station in Logan. The authors thank Steve Larsen (Western Dairy Center) for his technical assistance in cheesemaking, the panelists involved in this study for their commitment and willingness to participate, SIMS2000 personnel for their technical support and advice, Brian Pette (Western Dairy Center) for proximate analysis, and Michael Young (Department of Nutrition and Food Sciences, Utah State Universty, Logan) for helping in the chromatographic analysis. This paper was approved by the Utah Agricultural Experiment Station as paper \# 8018.

\section{REFERENCES}

American Public Health Association. 1992. Standard Methods for the Examination of Dairy Products. 16th ed. R. T. Marshall, ed. Am. Publ. Health Assoc. Inc., Washington, DC.

Aryana, K. J. 2007. Cheddar cheese manufactured with oil high in omega-3 fatty acids. Milchwissenschaft 62:167-170.

Avramis, C. A., H. Wang, B. W. McBride, T. C. Wright, and A. R. Hill. 2003. Physical and processing properties of milk, butter, and Cheddar cheese from cows fed supplemental fish meal. J. Dairy Sci. 86:2568-2576.

Borneo, R., D. Kocer, G. Ghai, B. J. Tepper, and M. V. Karwe. 2007. Stability and consumer acceptance of long-chain omega-3 fatty acids (eicosapentanoic acis 20:5, n-3 and docosahexaenoic acid, 22:6, n-3) in cream-filled sandwich cookies. J. Food Sci. 72:4954.

Curtis, J. M., N. Berrigan, and P. Dauphinee. 2008. The determination of n-3 fatty acid levels in Food Products containing microencapsulated fish oil using the one-step extraction method. Part 1: Measurement in the raw ingredient and in dry powdered foods. J. Am. Oil Chem. Soc. 85:297-305.

Ganeko, N., M. Shoda, I. Hirohara, A. Bhadra, T. Ishida, H. Matsuda, H. Takamura, and T. Matoba. 2008. Analysis of volatile flavor compounds of sardine (Sardinops melanstica) by solid phase microextraction. J. Food Sci. 73:S83-S88.

Kolanowski, W., F. Swiderski, D. Jaworska, and S. Berger. 2004. Stability, sensory quality, texture properties and nutritional value of fish oil-enriched spreadable fat. J. Sci. Food Agric. 84:21352141.

Kolanowski, W., and J. Weißbrodt. 2007. Sensory quality of dairy products fortified with fish oil. Int. Dairy J. 17:1248-1253.

Kris-Etherton, P. M., W. S. Harris, and L. J. Appel 2003. Omega-3 fatty acids and cardiovascular disease: New recommendations from the American Heart Association. Arterioscler. Thromb. Vasc. Biol. 23:151-152.

Lock, A. L., and D. E. Bauman. 2004. Modifying milk fat composition of dairy cows to enhance fatty acids beneficial to human health. Lipids 39:1197-1206.

Meilgaard, M. C., G. V. Civille, and B. T. Carr. 2007. Chapter 9: Selection and training of panel members. Sensory Evaluation Techniques. 4th ed. CRC Press, New York, NY.

Metcalf, R. G., M. J. James, E. Mantzioris, and L. G. Cleland. 2003 A practical approach to increasing intake of $n-3$ polyunsaturated fatty acids: Use of novel foods enriched with n-3 fats. Eur. J. Clin. Nutr. 57:1605-1612.

Murphy, K. J., B. J. Meyer, T. A. Mori, V. Burke, J. Mansour, C. S. Patch, L. C. Tapsell, M. Noakes, P. A. Clifton, A. Barden, I. B. Puddey, L. J. Beilin, and P. R. C. Howe. 2007. Impact of foods enriched with $\mathrm{n}-3$ long-chain polyunsaturated fatty acids on erythrocyte n-3 levels and cardiovascular risk factors. Br. J. Nutr. 97:749-757.

Rose, D. P., and J. M. Connolly. 1999. Omega-3 fatty acids as cancer chemopreventive agents. Pharmacol. Ther. 83:214-244.

Ruxton, C. H. S., S. C. Reed, M. J. A. Simpson, and K. J. Millington. 2004. The health benefits of omega-3 polyunsaturated fatty acids: A review of the evidence. J. Hum. Nutr. Dietet. 17:449-459.

Scollan, N., J. Hocquette, K. Nuernberg, D. Dannenberger, I. Richardson, and A. Moloney. 2006. Innovations in beef production systems that enhance the nutritional and health value of beef lipids and their relationship with meat quality. Meat Sci. 74:17-33.

Shipe, W. F., R. Bassette, D. D. Deane, W. L. Dunkley, E. G. Hammond, W. J. Harper, D. H. Kleyn, M. E. Morgan, J. H. Nelson, and R. A. Scanlan. 1978. Off-flavors of milk: Nomenclature, standards and bibliography. J. Dairy Sci. 61:855-869.

Sperling, R. I., A. I. Benincaso, C. T. Knoell, J. K. Larkin, K. F. Austen, and D. R. Robinson. 1993. Dietary omega-3 polyunsaturated fatty acids inhibit phosphoinositide formation and chemotaxis in neutrophils. J. Clin. Invest. 91:651-660.

USDA. 2005. Dietary Reference Intakes for Energy, Carbohydrate. Fiber, Fat, Fatty Acids, Cholesterol, Protein, and Amino Acids (2002/2005). http://www.iom.edu/Object.File/ Master/7/300/ Webtablemacro.pdf.

USDA. 2007. Nutrients Intakes from Food: Mean amounts Consumed per Individual, One day, 2003-2004. http://www.ars.usda.gov/ SP2UserFiles/Place/12355000/pdf/0304/ Table_1_NIF.pdf

Venkateshwarlu, G., M. B. Let, A. S. Meyer, and C. Jacobsen. 2004a. Chemical and olfactometric characterization of volatile flavor compounds in a fish oil enriched milk emulsion. J. Agric. Food Chem. 52:311-317.

Venkateshwarlu, G., M. B. Let, A. S. Meyer, and C. Jacobsen. 2004b. Modelling the sensory impact of defined combinations of volatile lipid oxidation products on fishy and metallic off-flavors. J. Agric. Food Chem. 52:1635-1641.

White, P. J. 2000. Flavor quality of fats and oils. Pages $341-370$ in Introduction to Fats and Oils Technology. 2nd ed. R. O'Brien, W. E. Farr, and P. J. Wan, ed. AOCS Press, Champaign, IL.

Williams, C. M. 2000. Dietary fatty acids and human health. Ann. Zootech. 49:165-180. 